\title{
ANALISIS TATA KELOLA TEKNOLOGI INFORMASI BIDANG MANAJEMEN PRODUKSI MENGGUNAKAN FRAMEWORK COBIT 5
}

\author{
Ilka Zufria, Anwar Fauzi, Danang Wahyu Wicaksono, Erwin Nasution \\ Sistem Informasi, Universitas Islam Negeri Sumatera Utara Medan \\ J1. IAIN No.1, Gaharu I, Medan 20335 \\ ilkazufria@uinsu.ac.id, fanwar004@gmail.com, nang.dev8@gmail.com, erwin.nasution@uinsu.ac.id
}

\begin{abstract}
Information Technology (IT) governance is used to build a system that helps companies in a process that involves stakeholders and related elements within the company. In order to provide maximum service to the community, a good Information Technology (IT) governance is needed. CV. Hydro Paint Medan is a company engaged in the automotive sector with the aim of providing high-quality services at competitive prices. The current increase in the role of IT in the company has actually been followed by changes in the company's business processes. The development of business strategy is always associated with IT strategy development. In this study, the authors aim to evaluate the information system governance at CV. Hydro Paint Medan with reference to the COBIT 5 framework. The results of this study indicate an assessment of the capability level of environmental conditions, conditions of the monitor, the potential for technology, and the use of innovation.
\end{abstract}

Keywords - Information Technology, Cobit 5, Capability Level, IT Governance, Information Systems

\begin{abstract}
Abstrak-Tata kelola Teknologi Informasi (TI) berguna untuk membangun sistem yang dapat membantu perusahaan dalam proses penggandengan para pemangku kepentingan dan elemen-elemen terkait pada perusahaan. Agar mampu memberikan pelayanan yang prima kepada pemangku kepentingan dan masyarakat, maka diperlukan sebuah tata kelola Teknologi Informasi (TI) yang baik. CV. Hydro Paint Medan adalah perusahaan yang bergerak dibidang otomotif bertujuan agar dapat memberikan pelayanan berkualitas tinggi dengan harga yang kompetitif. Peningkatan peran TI dalam perusahaan yang terjadi pada saat ini sebenarnya juga diikuti dengan area proses bisnis perusahaan. Perkembangan strategi bisnis selalu dikaitkan dengan pengembangan strategi TI-nya. Penelitian ini bertujuan melakukan evaluasi tata kelola sistem informasi di di CV. Hydro Paint Medan dengan acuan pada kerangka kerja COBIT 5. Hasil penelitian ini menunjukkan bahwa penilaian tentang tingkat kapabilitas kondisi lingkungan, kondisi dari monitor, potensi teknologi dan penggunaan inovasi.
\end{abstract}

Keywords - Kata Kunci - Teknologi Informasi, Cobit 5, Tingkat Kapabilitas, Tata Kelola TI, Sistem Informasi

\section{PENDAHULUAN}

Dengan semakin banyaknya teknologi, yang mampu memudahkan dalam menyelesaikan suatu permasalahan, maka banyak yang menggunakan sebuah sistem kedalam masyarakat maupun sebuah instansi. Tujuan audit sistem informasi adalah pengamanan aset, efektifitas sistem, efisiensi sistem, ketersediaan, kerahasiaan, kehandalan, dan menjaga integritas data [6].

IT Governance / Tata Kelola IT pada intinya adalah upaya menjamin pengelolaan teknologi informasi agar mendukung bahkan selaras dengan strategi kegiatan suatu enterprise yang dilakukan oleh dewan direksi, manajemen eksekutif, dan juga oleh manajemen teknologi informasi[11]. Tata kelola Sistem Informasi (SI)/Teknologi Informasi (TI) yang baik akan sangat mendukung aktivitas organisasi dalam mencapai sasaran yang meliputi visi dan misi organisasi karena diperlukan suatu keselarasan dalam strategi bisnis dan strategi SI/TI [14]. Infrastruktur TI memiliki peranan penting dalam keberhasilan kegiatan sehari-hari [4], salah satunya dalam dunia pendidikan misalnya memfasilitasi dan mendukung kegiatan penelitian seperti simulasi sistem, pengolahan data, dan lainnya . Tata kelola Teknologi Informasi (TI) mempertimbangkan dua hal, yaitu kemampuan layanan TI atas nilai bisnis dan juga mitigasi risiko TI yang didorong oleh keselarasan strategi TI dengan bisnis serta didorong oleh akuntabilitas organisasi. Kedua faktor tersebut harus didukung oleh sumber daya yang memadai dan diukur untuk menjamin hasilnya [1].

CV Hydropaint Medan merupakan suatu usaha jenis wirausaha menengah yang bergerak dalam bidang jasa pengecetan atau reparasi kendaraan seperti sepeda motor atau mobil dengan menggunakan Teknik Water Transfer Printing (WTP), yaitu Teknik pengecetan dengan metode celup.

Berdasarkan masalah yang dimiliki instansi tersebut, maka dibutuhkan penggunaan tata Kelola it yang dibantu oleh framework COBIT yang sesuai dengan kebutuhan CV Hydropaint. Selain itu, dengan penggunaan COBIT terdapat keunggulan yang tidak dimiliki oleh framework lainnya. Dimana COBIT 5 memiliki cakupan jangkauan masalah yang luas dengan mencangkup materi yang ada pada kerangka kerja lain. COBIT mengelompokkan semua aktivitas bisnis yang 
terjadi dalam organisasi menjadi 34 proses yang terbagi ke dalam empat buah domain proses, meliputi : Plan and Organise (10 proses), Acquire and Implement (7 proses), Deliver and Support (13 proses), Monitor and Evaluate (4 proses)[7]. Maka dari itu, peneliti menggunakan COBIT dengan versi COBIT 5 karena prosesnya lebih holistic, lengkap dan mencangkup aktifitas bisnis dan IT secara end-to-end.

Pada penelitian ini terdapat tujuan yaitu untuk mengetahui sejauh mana pengelolaan dan pemanfaatan teknologi informasi di CV. Hydro Paint Medan dan merekomendasikan usulan kebijakan pengelolaan TI yang efektif dan efesien menggunakan COBIT 5. Dimana hasil dari COBIT 5 ini adalah domain APO04 (Manage Inovation). Dari domain tersebut akan menghasilkan capability level, setelah itu gap analysis dari tata kelola sekarang dengan yang ditargetkan, kemudian memberikan rekomendasi perbaikan dan peningkatan tata kelola TI.

\section{METODE PENELITIAN}

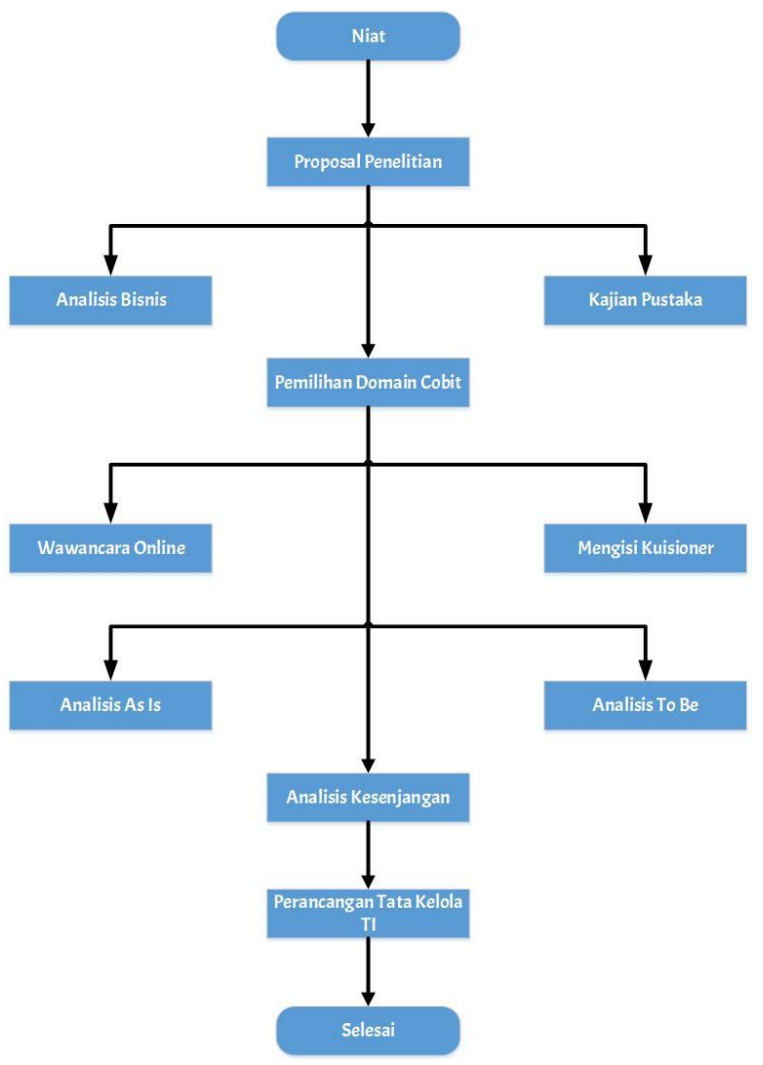

Gambar 1. Diagram Alur Penelitian

\section{A. Perencanaan Penelititan}

Tahap perencanaan diawali dengan melakukan observasi dan wawancara pada objek penelitian. Hal ini dilakukan untuk menemukan proses domain pada COBIT 5 yang terpilih sesuai dengan ruang lingkup kebutuhan penelitian[3].

\section{B. Pengumpulan data}

1. Pengumpulan data primer

Data primer merupakan data yang diperoleh langsung dari responden [9]. Peneliti melakukan pengumpulan data primer secara kualitatif dengan metode observasi, kuisioner dan wawancara. Peneliti melakukan observarsi di CV. Hydro Paint Medan, observasi ini dilihat melalui visi, misi serta tujuan yang ada nantinya menghasilkan analisis kondisi yang ada. Pada pengumpulan data dengan metode kuisioner dilakukan dengan cara membagikan kuisioner keunit kerja yang akan diaudit yang berisi berapa pertanyaan seputar implementasi dan tata kelola TI di unit kerja tersebut. Sedangkan Wawancara dilakukan dengan menanyakan berbagai macam pertanyaan secara langsung dengan beberapa responden.

\section{Mapping}

Menghitung rekapitulasi jawaban kuisioner :

$$
C=\frac{H}{J R} \times 100 \%
$$

Keterangan:

C : Rekapitulasi jawaban kusioner Capability Level

H : Jumlah jawaban kusioner Capability Level pada masing pilihan jawaban level 0 sampai 5 setiap aktivitas

JR : Jumlah responden/narasumber Hasil dan Pembahasan.

\section{Model Penilaian Kapabilitas}

Kapabilitas proses merupakan karakteristik dari kemampuan sebuah proses untuk mencapai tujuan bisnis saat ini ataupun saat mendatang (Putri, 2016). Penilaian kapabilitas proses dilakukan untuk mengidentifikasi level kapabilitas proses tertentu dan kemudian menentukan langkah selanjutnya untuk melakukan peningkatan terhadap kapabilitas proses tersebut (Hidayat \& Rahmat, 2015). Hasil penilaian capability level masing-masing proses dapat dilakukan dengan rumus rata-rata sebagai berikut : Capability Level $=$

$\frac{(1 x y 0)+(2 x y 1)+(3 x y 2)+(4 x y 3)+(5 x y 4)}{z}$

Keterangan :

Yn (y0...y5) : Jumlah proses yang berada di level $\mathrm{n}$

$\mathrm{Z} \quad$ : Jumlah proses yang dievaluasi

(Elly \& Halim, 2016)

\section{Pemilihan Domain Cobit 5}

COBIT 5 mempunyai kompromi antara dimensi horisontal dan vertikal yang lebih baik dari standarstandar lainnya[5]. COBIT mempunyai spektrum proses TI yang lebih luas dan lebih mendetail. Pemilihan domain COBIT bertujuan agar proses yang dibahas sesuai dengan tujuan bisnis dari perusahaan. Proses tata kelola yang akan digunakan adalah dengan menggunakan COBIT 5 dengan Domain APO (Align, 
Plan, Organize) karena memberikan panduan solusi penyediaan layanan dan dukungan strategi serta mengidentifikasi resiko yang merupakan cara terbaik TI dalam berkontribusi pada pencapaian tujuan Organisasi[12].

\section{Analisis Kesenjangan.}

Analisis kesenjangan dilakukan untuk mengidentifkasi perbaikan yang diperlukan untuk meningkatkan tingkat kapabilitas berdasarkan atribut pada framework COBIT5[8]. Hasil analisis ini adalah saran perbaikan untuk tata kelola TI terkait proses mengawasi, mengevaluasi, menilai kinerja dan kesesuaian dalam pelaksanaan penyediaan layanan egovernment pada CV. Hydro Paint Medan. Analisis kesenjangan (gap analysis) dilakukan untuk mencari berapa selisih antara level tingkat kapabilitas yang diperoleh saat ini dengan level tingkat yang diharapkan[15].

\section{HASIL DAN PEMBAHASAN}

\section{A. Pemilihan Domain Cobit.}

Pada tahap ini dilakukan penetapan domain yang terdapat pada COBIT 5 yang selanjutnya akan dievaluasi di CV Hydropaint Medan. Agar implementasi IT Governance CV. Hydro Paint Medan dapat berlangsung secara efektif, organisasi harus dapat mengevaluasi dan menilai sejauh mana IT Governance yang sekarang berlangsung dan mengidentifikasi peningkatan yang dapat dilakukan [13]. Pemilihan domain COBIT dilakukan dengan mempelajari dokumen bisnis CV Hydropaint Medan dan melakukan wawancara. Berdasarkan hasil analisa dokumen bisnis dan hasil wawancara, maka dipilih salah satu tujuan umum perusahaan yang terdapat Pada matriks tujuan bisnis sesuai dengan tujuan bisnis di CV Hydropaint Medan dengan tujuan umumnya No. 17 Knowledge, expertise and initiatives for business innovation (Inovasi mengacu pada penciptaan proses, produk, dan ide yang lebih efektif).

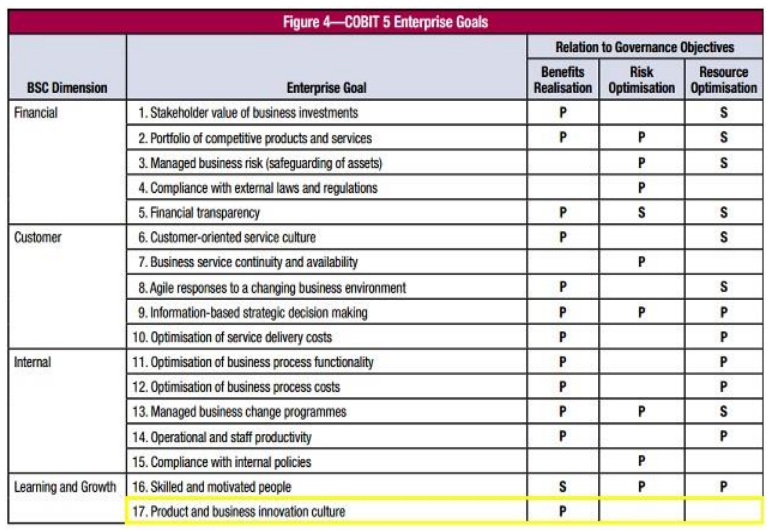

Gambar 2. COBIT 5 Enterprise Goals[16]

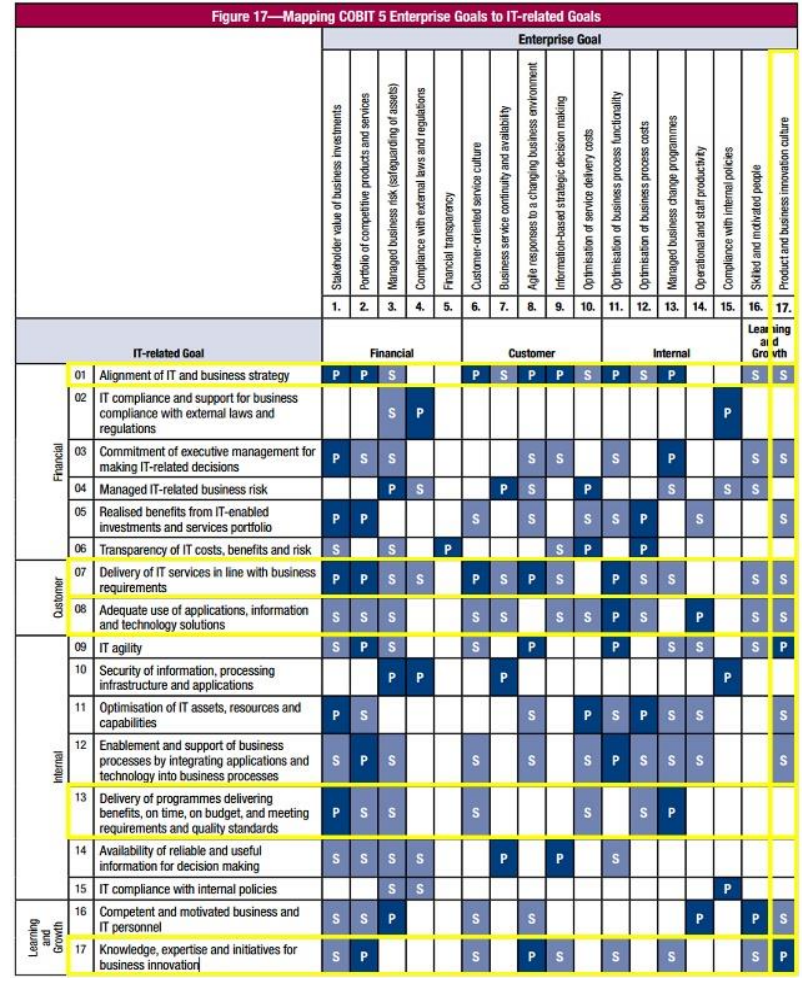

Gambar 3. Mapping COBIT 5 Enterprise Goals to ITRelated Goals [16]

Sehubungan dengan misi CV Hydropaint Medan, membuat Inovasi mengacu pada penciptaan proses, produk, dan ide yang lebih efektif, sehingga IT-Related Goals COBIT 5 yang sesuai dengan keadaan di CV Hydropaint Medan adalah Knowledge expertise and initiatives for business innovation (Gambar 3). Mapping COBIT 5 IT-Related Golas to Process[16]

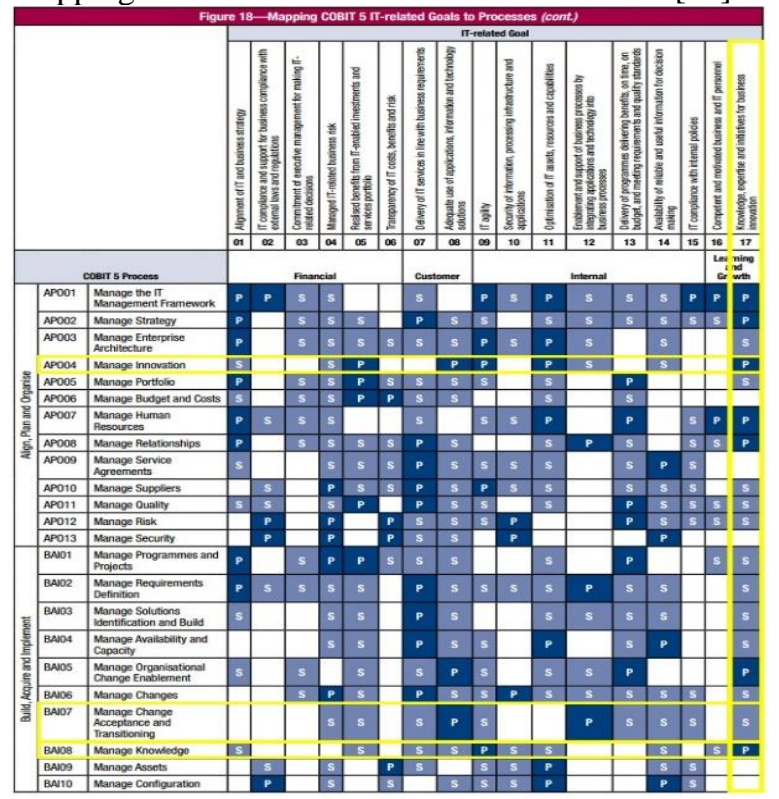

Gambar 4. Mapping COBIT 5 IT-Related Golas to Process[16] 
Setelah itu langkah selanjutnya memilih domain yang sesuai dengan pemetaan pada IT-Related Goals COBIT 5 yang menghasilkan 3 proses COBIT yang primary: APO04 Manage Innovation (Memanajemen Inovasi). Dari tiga proses tersebut hanya dipilih satu proses yang disesuaikan dengan CV Hydropaint Medan. Proses Domain itu adalah Proses APO04 Manage Innovation (Memanajemen Inovasi), dimana APO04 merupakan kelola hubungan antara bisnis dengan TI secara formal dan transparan yang memastikan focus untuk mencapai tujuan bersama dan hasil perusahan yang sukses dalam mendukung tujuan strategis bersama serta dalam batasan anggaran dan toleransi risiko. Dengan memiliki tujuan dalam menciptakan hasil yang lebih baik, meningkatkan kepercayaan TI dan penggunaan sumber daya secara efektif. APO04 Ini terdapat beberapa sub proses yaitu:

1. APO04.01 (Menciptakan lingkungan yang kondusif untuk inovasi).

2. APO04.02 (Pertahankan pemahaman tentang lingkungan perusahaan).

3. APO04.03 (Monitor dan pindai teknologinya lingkungan Hidup).

4. APO04.04 (Menilai potensi teknologi yang muncul dan ide-ide inovasi).

5. APO04.05 (Merekomendasikan inisiatif lebih lanjut yang sesuai).

6. APO04.06 (Pantau implementasi dan penggunaan inovasi).

B. Hasil Rekapitulasi Kuisioner APOO4

1. Hasil Rekapitulasi APO04.01

Tabel 1. Hasil Rekapitulasi APO04.01

\begin{tabular}{|c|c|c|c|c|c|c|}
\hline \multirow{2}{*}{$\begin{array}{c}\text { Aktivitas } \\
\text { Proses }\end{array}$} & \multicolumn{6}{|c|}{ Distribusi Jawaban (\%) } \\
\cline { 2 - 7 } & $\mathbf{0}$ & $\mathbf{1}$ & $\mathbf{2}$ & $\mathbf{3}$ & $\mathbf{4}$ & $\mathbf{5}$ \\
\hline $\begin{array}{c}\text { Kondisi Saat } \\
\text { Ini }\end{array}$ & 0 & 30 & 40 & 20 & 10 & 0 \\
\hline $\begin{array}{c}\text { Kondisi Yang } \\
\text { Diharapkan }\end{array}$ & 8 & 0 & 4 & 48 & 20 & 52 \\
\hline
\end{tabular}

2. Hasil Rekapitulasi APO04.02

Tabel 2. Hasil Rekapitulasi APO04.02

\begin{tabular}{|c|c|c|c|c|c|c|}
\hline \multirow{2}{*}{$\begin{array}{c}\text { Aktivitas } \\
\text { Proses }\end{array}$} & \multicolumn{5}{|c|}{ Distribusi Jawaban (\%) } \\
\cline { 2 - 7 } & $\mathbf{0}$ & $\mathbf{1}$ & $\mathbf{2}$ & $\mathbf{3}$ & $\mathbf{4}$ & $\mathbf{5}$ \\
\hline Kondisi Saat Ini & 0 & 50 & 17 & 33 & 0 & 0 \\
\hline $\begin{array}{c}\text { Kondisi Yang } \\
\text { Diharapkan }\end{array}$ & 0 & 66 & 17 & 17 & 0 & 0 \\
\hline
\end{tabular}

3. Hasil Rekapitulasi APO04.03

Tabel 3. Hasil Rekapitulasi APO04.03

\begin{tabular}{|c|c|c|c|c|c|c|}
\hline \multirow{2}{*}{$\begin{array}{c}\text { Aktivitas } \\
\text { Proses }\end{array}$} & \multicolumn{5}{|c|}{ Distribusi Jawaban (\%) } \\
\cline { 2 - 7 } & $\mathbf{0}$ & $\mathbf{1}$ & $\mathbf{2}$ & $\mathbf{3}$ & $\mathbf{4}$ & $\mathbf{5}$ \\
\hline Kondisi Saat Ini & 0 & 13 & 75 & 0 & 0 & 13 \\
\hline $\begin{array}{c}\text { Kondisi Yang } \\
\text { Diharapkan }\end{array}$ & 25 & 13 & 0 & 13 & & 0 \\
\hline
\end{tabular}

4. Hasil Rekapitulasi APO04.04

Tabel 4. Hasil Rekapitulasi APO04.04

\begin{tabular}{|c|c|c|c|c|c|c|}
\hline \multirow{2}{*}{$\begin{array}{c}\text { Aktivitas } \\
\text { Proses }\end{array}$} & \multicolumn{5}{|c|}{ Distribusi Jawaban (\%) } \\
\cline { 2 - 7 } & $\mathbf{0}$ & $\mathbf{1}$ & $\mathbf{2}$ & $\mathbf{3}$ & $\mathbf{4}$ & $\mathbf{5}$ \\
\hline $\begin{array}{c}\text { Kondisi Saat } \\
\text { Ini }\end{array}$ & 0 & 10 & 40 & 50 & 20 & 0 \\
\hline $\begin{array}{c}\text { Kondisi Yang } \\
\text { Diharapkan }\end{array}$ & 10 & 50 & 30 & 10 & 0 & 0 \\
\hline
\end{tabular}

5. Hasil Rekapitulasi APO04.05

Tabel 5. Hasil Rekapitulasi APO04.05

\begin{tabular}{|c|c|c|c|c|c|c|}
\hline \multirow{2}{*}{$\begin{array}{c}\text { Aktivitas } \\
\text { Proses }\end{array}$} & \multicolumn{5}{|c|}{ Distribusi Jawaban (\%) } \\
\cline { 2 - 7 } & $\mathbf{0}$ & $\mathbf{1}$ & $\mathbf{2}$ & $\mathbf{3}$ & $\mathbf{4}$ & $\mathbf{5}$ \\
\hline $\begin{array}{c}\text { Kondisi Saat } \\
\text { Ini }\end{array}$ & 0 & 13 & 25 & 13 & 25 & 25 \\
\hline $\begin{array}{c}\text { Kondisi Yang } \\
\text { Diharapkan }\end{array}$ & 63 & 13 & 0 & 0 & 0 & 0 \\
\hline
\end{tabular}

6. Hasil Rekapitulasi APO04.06

Tabel 6. Hasil Rekapitulasi APO04.06

\begin{tabular}{|c|c|c|c|c|c|c|}
\hline \multirow{2}{*}{$\begin{array}{c}\text { Aktivitas } \\
\text { Proses }\end{array}$} & \multicolumn{5}{|c|}{ Distribusi Jawaban (\%) } \\
\cline { 2 - 7 } & $\mathbf{0}$ & $\mathbf{1}$ & $\mathbf{2}$ & $\mathbf{3}$ & $\mathbf{4}$ & $\mathbf{5}$ \\
\hline $\begin{array}{c}\text { Kondisi Saat } \\
\text { Ini }\end{array}$ & 13 & 13 & 38 & 13 & 0 & 0 \\
\hline $\begin{array}{c}\text { Kondisi Yang } \\
\text { Diharapkan }\end{array}$ & 13 & 63 & 0 & 13 & & 0 \\
\hline
\end{tabular}




\section{Menentukan Nilai Kapabilitas Domain APO04}

1. Nilai Kapabilitas APO04.01

As Is APO04.01

To Be APO04.01

$$
N K=\frac{(0 \times 0)+(30 \times 1)+(40 \times 20)+(20 \times 3)+(10 \times 4)+(0 \times 5)}{100}=2.1
$$

$$
N K=\frac{(30 \times 0)+(20 \times 1)+(30 \times 2)+(0 \times 3)+(0 \times 4)+(0 \times 5)}{100}=0.8
$$

2. Nilai Kapabilitas APO04.02

As Is APO04.02

To Be APO04.02

$$
N K=\frac{(0 \times 0)+(50 \times 1)+(17 \times 2)+(33 \times 3)+(0 \times 4)+(0 \times 5)}{100}=1.83
$$

$$
N K=\frac{(0 \times 0)+(66 \times 1)+(17 \times 2)+(17 \times 3)+(0 \times 0)+(0 \times 0)}{100}=1.51
$$

3. Nilai Kapabilitas APO04.03

As Is APO04.03

To Be APO04.03

$$
N K=\frac{(0 \times 0)+(13 \times 1)+(75 \times 2)+(0 \times 0)+(0 \times 0)+(13 \times 5)}{100}=2.28
$$

$$
N K=\frac{(25 \times 0)+(13 \times 1)+(0 \times 2)+(13 \times 3)+(13 \times 4)+(0 \times 5)}{100}=1.04
$$

4. Nilai Kapabilitas APO04.04

As Is APO04.04

To Be APO04.04

$$
N K=\frac{(0 \times 0)+(10 \times 1)+(30 \times 2)+(30 \times 3)+(30 \times 4)+(0 \times 0)}{100}=1.7
$$

$$
N K=\frac{(10 \times 0)+(50 \times 1)+(30 \times 2)+(10 \times 3)+(0 \times 4)+(0 \times 5)}{100}=1.4
$$

\section{Nilai Kapabilitas APO04.05}

As Is APO04.05

To Be APO04.05

$$
N K=\frac{(0 \times 0)+(13 \times 1)+(25 \times 2)+(13 \times 3)+25 \times 4)+(25 \times 5)}{100}=4.27
$$

$$
N K=\frac{(63 \times 0)+(13 \times 1)+(0 \times 2)+(0 \times 3)+(0 \times 4)+(0 \times 5)}{100}=0.13
$$

6. Nilai Kapabilitas APO04.06

As Is APO04.06

To Be APO04.06

$$
N K=\frac{(13 \times 0)+(13 \times 1)+(38 \times 2)+(13 \times 3)+(0 \times 4)+(25 \times 5)}{100}=3.53
$$

$$
N K=\frac{(13 \times 0)+(63 \times 1)+(0 \times 2)+(13 \times 3)+(0 \times 4)+(0 \times 5)}{100}=1.02
$$


D. Tingkat Kapabilitas APO04 manage Inovation (Mengelola Inovasi)

Tabel 7. Nilai dan Tingkat Kapabalitas

\begin{tabular}{|c|c|c|c|c|c|}
\hline \multirow{2}{*}{ No } & \multirow{2}{*}{ Sub Proses } & \multicolumn{2}{|c|}{$\begin{array}{c}\text { Nilai } \\
\text { Kapabilitas }\end{array}$} & \multicolumn{2}{|c|}{$\begin{array}{c}\text { Tingkat } \\
\text { Kapabilitas }\end{array}$} \\
\hline & & As is & To be & As is & To be \\
\hline 1 & APO04.01 & 2,1 & 0,8 & 3 & 2 \\
\hline 2 & APO04.02 & 1,83 & 1,51 & 3 & 5 \\
\hline 3 & APO04.03 & 2,28 & 1,04 & 3 & 1 \\
\hline 4 & APO04.04 & 1,7 & 1,4 & 3 & 1 \\
\hline 5 & APO04.05 & 4,27 & 0,13 & 3 & 2 \\
\hline 6 & APO04.06 & 3,53 & 1,02 & 3 & 1 \\
\hline & Rata - Rata & 2,61 & 0,98 & 3 & 2 \\
\hline
\end{tabular}

Dari tabel diatas dapat disimpulkan bahwa pada proses ensure resource optimization di CV Hydropaint Medan untuk kondisi saat ini (as is) memperoleh nilai 2,32 atau bisa dikatakan berada di tingkat kapabilitas level 2 yaitu Managed Process, artinya pada proses APO04 (Manage Inovation) di CV. Hydro Paint Medan sudah adanya pengelolaan pada optimasi sumber daya yang mencangkup perencanaan, monitoring dan penyesuaian pada pelaksanaan proses.

Sedangkan, pada kondisi yang diharapkan (to be) pada proses ensure resource optimization di CV. Hydro Paint Medan memperoleh nilai 3,4 dengan tingkat kapabilitas level 3, dimana tahap ini harus diterapakan Established Process, artinya proses APO04 (Manage Relationship) di CV. Hydropaint Medan diharapkan terdapat adanya implementasi menggunakan proses yang telah didefenisikan dan mampu mencapai hasil dari tujuan yang diharapkan.

\section{E. Analisis Kesenjangan}

Menurut perhitungan penilaian yang telah dilakukan pada tahap data validation, untuk kondisi saat ini (as is), hal ini dapat di artikan bahwa pada proses APO04 saat ini berada pada level 3. Berikut tabel di bawah ini akan menjelaskan temuan, gap, dan rekomendasi untuk perbaikan pada sub domain yang ada pada proses APO04.

Tabel 8. Temuan, Gap. Dan Rekomendasi

\begin{tabular}{|l|l|l|}
\hline \multicolumn{1}{|c|}{ Temuan } & \multicolumn{1}{|c|}{ GPO04-Mengelola Inovasi } \\
\hline $\begin{array}{l}\text { Telah melakukan } \\
\text { proses inisiatif dan }\end{array}$ & $\begin{array}{l}\text { Belum adanya } \\
\text { perencanaan untuk } \\
\text { ketersediaan }\end{array}$ & $\begin{array}{l}\text { Memaksimalkan perencanaan untuk inisiatif } \\
\text { dalam melaksanakansuatu rencana demi }\end{array}$ \\
$\begin{array}{l}\text { kemampuan TI dan } \\
\text { migrasi pada }\end{array}$ & kemampan inisiatif dan & terwujudnya organisasi yang lebih baik. \\
lingkungan saat ini & perencanaan strategi TI & \\
\hline
\end{tabular}

\section{KESIMPULAN}

Berdasarkan penelitian, pembahasan dan analisis dari kuesioner, obesrvasi dan wawancara mengenai tahapan audit yang telah dilakukan, dapat diambil kesimpulan untuk setiap proses COBIT 5.0 yang di gunakan sebagai berikut yaitu pada domain APO04.

Pada proses APO04 membahas tentang manajemen inovasi. Pada proses ini didapatkan nilai kapabilitas sebesar 2,61 untuk keadaan as is (keadaan saat ini), Sedangkan untuk keadaan to be (keadaan yang diharapkan) didapatkan nilai kapabilitas sebesar 0,98 .

Hal ini berarti pada CV. Hydropaint Medan harus memenuhi syarat indicator kapabilitas proses pada level 2 yang belum terpenuhi seperti membuat dokumentasi mengenai pengelolaan hubungan antara bisnis dengan TI, membuat SOP yang berisi mengatur koordinasi antar pihak, membuat acara yang dapat membuat saling berhubungan antara dinas dan pihak lainnya.

Adapun yang dapat dilakukan pada penelitian selanjutnya dalam pengembangan penelitian ini yaitu dengan melakukan studi kasus untuk proses lainnya seperti APO01, APO02, APO03, APO05, APO06, APO07, APO08 agar didapatkan rekomendasi yang lebih baik lagi untuk evaluasi tatakelola infrastruktur TI yang dimanfaatkan oleh CV. Hydropaint Medan.

CV. Hydropaint Medan juga diharapkan untuk menyusun dan menetapkan pedoman berdasarkan panduan dari COBIT 5 untuk proses yang dievaluasi.

\section{DAFTAR PUSTAKA}

[1]. Andono, B., Suroso, A. I., \& Purnaningsih, N. Tata Kelola Sistem Informasi pada Perusahaan Pelayaran Lepas Pantai. Jurnal Aplikasi Bisnis Dan Manajemen, 3(2), 313-323. 2017. https://doi.org/10.17358/jabm.3.2.313

[2]. Elly, \& Halim, F. Evaluasi Tatakelola Infrastruktur Ti Dengan Framework Cobit 5 ( Studi Kasus : Stmik - Stie Mikroskil ). Sebatik, 5, 74-82. 2016.

[3]. Fajarwati, S., Sarmini, S., \& Septiana, Y. Evaluasi Tata Kelola Teknologi Informasi Menggunakan Kerangka Kerja COBIT 5. JUITA: Jurnal $\begin{array}{llll}\text { Informatika, } & 6(2), & 73 . & \end{array}$ https://doi.org/10.30595/juita.v6i2. 
[4]. Fryonanda, H., Sokoco, H., \& Nurhadryani, Y. Evaluasi Infrastruktur Teknologi Informasi Dengan Cobit 5 Dan Itil V3. JUTI: Jurnal Ilmiah Teknologi Informasi, 17(1), 1. 2019. https://doi.org/10.12962/j24068535.v17i1.a717

[5]. Kaban, I. E. Tata kelola teknologi informasi. 1-5. 2009.

[6]. Kusbandono, H., \& Ariyadi, D. Rekomendasi Tata Kelola Aset Ti Berdasarkan Cobit 5. Simetris: Jurnal Teknik Mesin, Elektro Dan Ilmu Komputer, 9(2), 1015-1020. 2018 https://doi.org/10.24176/simet.v9i2.2531

[7]. Megawati, M., \& Amrullah, F. Evaluasi Tingkat Kematangan Teknologi Informasi Dengan Menggunakan Model Maturity Level Cobit 4.1 (Studi Kasus Pt. Bri Cabang Bangkinang). Jurnal Sains Dan Teknologi Industri, 12(1), 99-105. 2014.

http://ejournal.uinsuska.ac.id/index.php/sitekin/ar ticle/view/779/728

[8]. Prasojo, H. P., \& Pujiono. Analisis Tata Kelola Teknologi Informasi Dengan Menggunakan Framework Cobit 5 Domain DSS01 ( Manage Operations ) Pada BPS Provinsi Jawa Tengah. Journal JOINS Udinus, 1(x), 67-76. 2017.

[9]. Purnawan, I. K. A. Pedoman Tata Kelola Teknologi Informasi Menggunakan It Governance Design Frame Work (Cobit) Pada PT. X. Lontar Komputer: Jurnal Ilmiah Teknologi Informasi, 6(3), 200.2015 https://doi.org/10.24843/lkjiti.2015.v06.i03.p07

[10]. Putri, R. E. Penilaian Kapabilitas Proses Tata Kelola TI Berdasarkan Proses DSS01 Pada Framework COBIT 5. Jurnal CoreIT, 2(1), 41-54. 2016.
[11]. Savira, R. B., \& Sari, W. S.. Analisis IT Governance dengan Domain MEA01 Dalam Pelaksanaan E-Health Menggunakan Kerangka Kerja COBIT 5 pada Dinas Kesehatan Provinsi Jawa Tengah. Techno, 15(1), 48-57. 2016.

[12]. Sinaga, E. M., \& Waluyo, D. E. Analisis Tingkat Kapabilitas Sistem Informasi Layanan Pengaduan Menggunakan Kerangka Kerja COBIT 5 DOMAIN APO (APO11) Pada LaporGub. Journal of Information System, 79. 2016.

[13]. Suradi, A., \& Wiyanta, S. Framework Cobit Untuk Identifikasi Tingkat Kematangan Tata Kelola Teknologi Informasi: Studi. Khazanah Informatika: Jurnal Ilmu Komputer Dan Informatika, 3(1), 38-42. 2017.

[14]. Waluyan, G., Manuputty, A. D., Teknologi, F., Universitas, I., \& Satya, K. Evaluasi Kinerja Tata Kelola TI Terhadap Penerapan Sistem Informasi Starclick Framework COBIT 5 ( Studi Kasus : PT - Telekomunikasi Indonesia, Tbk Semarang ). 02(03), 157-166. 2016.

[15]. Zhafarina, V., \& Wibowo, S. Evaluasi Sistem EGoverment Berdasarkan Cobit 5 Dengan Domain MEA01 Pada Badan Kepegawaian Daerah Kota Semarang. JOINS (Journal of Information System), 1(2), 128-139. 2016. https://doi.org/10.33633/JOINS.V1I2.1304

[16]. ISACA.. COBIT 5: A business framework for Governance and Management of Enterprise IT. Introduction to COBIT. 2012. https://doi.org/http://dx.doi.org/10.1016/j.vetmic. 2015.02.021 